Article

\title{
Lesson Learned from the Power of Open Data: Resolving the Mask Shortage Problem Caused by COVID-19 in South Korea
}

\author{
Haklae Kim ${ }^{+}(\mathbb{C}$
}

check for

updates

Citation: Kim, H. Lesson Learned from the Power of Open Data: Resolving the Mask Shortage Problem Caused by COVID-19 in South Korea. Sustainability 2021, 13, 278. https://doi.org/10.3390/su13010278

Received: 8 December 2020 Accepted: 25 December 2020 Published: 30 December 2020

Publisher's Note: MDPI stays neutral with regard to jurisdictional claims in published maps and institutional affiliations.

Copyright: () 2020 by the authors. Licensee MDPI, Basel, Switzerland. This article is an open access article distributed under the terms and conditions of the Creative Commons Attribution (CC BY) license (https: / / creativecommons.org/ licenses/by/4.0/).
Department of Library and Information Science, Chung-Ang University, Seoul 06974, Korea; haklaekim@cau.ac.kr † Current address: 84 Heukseok-ro, Heukseok-dong, Dongjak-gu, Seoul 06974, Korea.

\begin{abstract}
COVID-19 is spreading globally and causing severe damage across different sectors including social culture, politics, and economy. Governments worldwide are responding in various ways to prevent the spread of COVID-19 and to protect the health and safety of citizens. South Korea is escaping the crisis through rapid and early inspection with ICT technology, isolation for confirmed cases, and transparency and communication through public-private partnerships. This paper presents how face mask shortages can be managed through the disclosure of government data and with effective online services. This study shows how South Korea enhances government transparency and that combining open data with ICT technologies can effectively solve social problems during the COVID-19 pandemic.
\end{abstract}

Keywords: COVID-19; open data; mask shortage; government data

\section{Introduction}

The emergence of COVID-19 is confining billions of people worldwide and has become a great challenge for healthcare services and other industries as a whole [1]. Since the first recorded case in China at the end of 2019, SARS-CoV-2 has spread worldwide and been declared a pandemic by the World Health Organization (WHO) [2,3]. From 31 December, 2019 to December 24, 2020, 79,022,921 positive COVID-19 cases and 1,736,298 deaths were confirmed globally [4]. The damage caused by the virus affects public health and political, social, and economic issues [5,6]. Because SARS-CoV-2 is spreading rapidly and vaccines and treatments are yet to be developed [7], countries worldwide are trying to prevent the spread of the infectious disease by minimizing the contact between people by applying social distancing and quarantine safety measures and/or by limiting crossborder mobility [8]. For example, the United States, various countries in the European Union, and China with large numbers of confirmed cases are implementing high-intensity social distancing measures that restrict entry into foreign countries or inhibit citizens from gathering and leaving their homes $[9,10]$. In addition, as interest in personal hygiene and public health has increased, there has been a worldwide shortage of personal medical supplies, such as masks, hand cleaners, and thermometers [11].

The first confirmed case of COVID-19 in Korea was reported on 20 January 2020. During the rapid spread of SARS-CoV-2, citizens voluntarily adhered to the government's public advice and guidelines regarding prevention [12]. The government recommended face masks as the most basic means for preventing infection at the individual level and the spread of viruses. Although there was debate over whether masks are effective for preventing the spread of SARS-CoV-2 [13], face masks are essential for personal hygiene and considered an important means for preventing the transmission of viruses to others in Korea. The lack of personal protective equipment and rapid price increases were risk factors that increased the citizens' concerns [14]. In particular, numerous citizens complained about face mask shortages [15]. Because the government was unable to respond effectively to the lack of masks at the beginning of the COVID-19 
outbreak, it implemented a mask distribution policy to address risk factors, such as the nationwide spread of SARS-CoV-2 [16].

This paper introduces a case of data-driven government policy and decision-making to prevent the spread of COVID-19 in Korea. In the process of solving the mask shortage problem triggered by the rapid spread of the COVID-19 virus, the usefulness of the data released by the government will be confirmed, and the importance of open data will be introduced. More specifically, the mask policy of the Korean Government and the public mask distribution system are introduced, and the mitigation of the mask shortage problem through the disclosure of government data and public-private partnerships is presented.

The remainder of this paper is organized as follows: Section 2 discusses the personal protective methods and benefits of wearing a face mask for preventing COVID-19 infection. Section 3 summarizes the spread and Korea's response to the COVID-19 outbreak, and outlines the mask shortage problem in Korea. Moreover, Section 4 introduces the mask distribution policies and presents an online service for scrutinizing mask stocks through public-private partnerships. Section 5 summarizes the lessons learned from the results and further discussions, and Section 6 concludes the paper.

\section{Related Works}

The WHO declared the 'Public Health Emergency of International Concern' owing to the new coronavirus infections and recommended corrective hygiene management and actions to prevent the spread of COVID-19 [17]. These safety measures include frequent handwashing with alcohol-based hand sanitizers or soap and water [18]. Personal protective equipment is crucial for reducing the risk of viral transmission [19]. However, the mask use guidelines differ according to the country and institution [20]. The WHO emphasized that 'wearing a medical mask is one of the prevention measures' that can limit the spread of certain respiratory viral diseases. However, 'the use of a mask alone is insufficient to provide an adequate level of protection' [21]. Nevertheless, various researchers have reported the positive potential of face masks regarding SARS-CoV-2 transmission [22-25]. Stutt et al. [26] proposed a modeling framework for assessing the effectiveness of face masks in the mitigation of the COVID-19 spread and emphasized the need of well-designed studies of face masks based on large populations.

Although each country has different standards for quarantine masks, these masks have similar blocking characteristics [27]. In Europe, the masks FFP1 (a blocking rate of $80 \%$ or higher), FFP2 (a blocking rate of $94 \%$ or higher), and FFP3 (a blocking rate of $99 \%$ or higher) are classified according to grades [27]. The N95 in the United States and KF94 in Korea have similar blocking rates; however, the detailed functions vary. The N95 masks are only subjected to sodium chloride $(\mathrm{NaCl})$ particle blocking tests, while KF94 masks must pass both sodium chloride and paraffin oil tests [28]. Therefore, N95 masks are unsuitable for the protection against liquid microparticles. In July 2009, the National Institute of Food and Drug Safety Evaluation (NIFDSE) [29] in Korea established guidelines for face masks to prevent citizens from inhaling dust from sand or dry soil particles [28]. Because fine-dust pollution has become a severe problem, the Ministry of Food and Drug Safety (MFDS) revised the previous mask guidelines and has updated them continuously since November 2014 [29]. The face mask (which is licensed as a medical product) is designed to protect respiratory organs from harmful particles, such as yellow and fine dust or from infectious sources. It is functionally different from a cold mask, which protects the face from the cold. As shown in Table 1, health masks are classified into three categories according to their particle blocking characteristics: KF80, KF94, and KF99; KF is the acronym of 'Korea Filter', and the numbers indicate the filtering performance [28]; KF80 can filter out $80 \%$ of fine particles with an average size of $0.6 \mu \mathrm{m}$, and KF94 and KF99 can filter out $94 \%$ and $99 \%$ of particles with average sizes of $0.4 \mu \mathrm{m}$, respectively [30]. The larger the number, the greater the blocking effect for fine particles. However, a mask should be selected according to the degree of fine dust contamination and individual respiratory conditions. The South Korean 
Government recommended the use of masks (in particular, the KF94 mask) to prevent the spread of infections.

Table 1. Features of health masks (National Institute of Food and Drug Safety Evaluation (NIFDSE), 2019).

\begin{tabular}{|c|c|c|c|}
\hline Grade & Dust Capture Efficiency (\%) & Leakage Rate & Air-Absorption Resistance in the Facial Area \\
\hline KF80 & Average particle size approximately $0.6 \mu \mathrm{m}$ over $80 \%$ & Below $25 \%$ & Below $60 \mathrm{~Pa}$ or Below $6.2 \mathrm{~mm} \mathrm{H}_{2} \mathrm{O}$ \\
\hline KF94 & Average particle size approximately $0.4 \mu \mathrm{m}$ over $94 \%$ & Below 11\% & 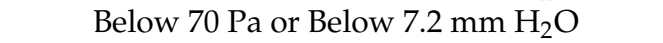 \\
\hline KF99 & Average particle size approximately $0.4 \mu \mathrm{m}$ over $99 \%$ & Below 5\% & Below $100 \mathrm{~Pa}$ or Below $10.3 \mathrm{~mm} \mathrm{H}_{2} \mathrm{O}$ \\
\hline
\end{tabular}

\section{Response to COVID-19 in Korea}

Korea is closely related to China owing to their geographic, economic, cultural, and political characteristics. Because of the increasing number of confirmed cases and deaths in China, Korean citizens are concerned about the impact of the virus. During Korea's New Year holidays (24-27 January 2020), the sales of personal hygiene products, such as masks and hand sanitizers, increased significantly. Compared to the sales of the previous week, Gmarket's sales of related products soared: mask sales increased by $9118 \%$, hand wash sales by $3545 \%$, liquid hand wash sales by $166,619 \%$, and hand sanitizer sales by $4496 \%$ [31].

However, the Korean Government responded only slowly when the number of cases increased gradually. As shown in Figure 1, Korea's first positive case was confirmed on 20 January, and the growth rate of new cases remained relatively low for approximately a month thereafter. There were 28 confirmed cases by 10 February, with no new cases between the 11-15 February. Therefore, the government announced that the COVID-19 outbreak was under control and that quarantine authorities had prevented domestic influx and community outbreaks [32]. On 12 February, the government confirmed there was no need to postpone or cancel collective events [33]. President Moon Jae-in stated that quarantine management was sufficient and predicted that COVID-19 would 'disappear long before' 13 February [34]. However, from the 16th of February, many cases of an unknown infection were reported (556 confirmed cases within a week), which indicated a rapid spread. As a result, the criticism of the government's response and demand for an active response increased [35].

\section{Confirmed Cases of Korea and China: From January to April 2020}

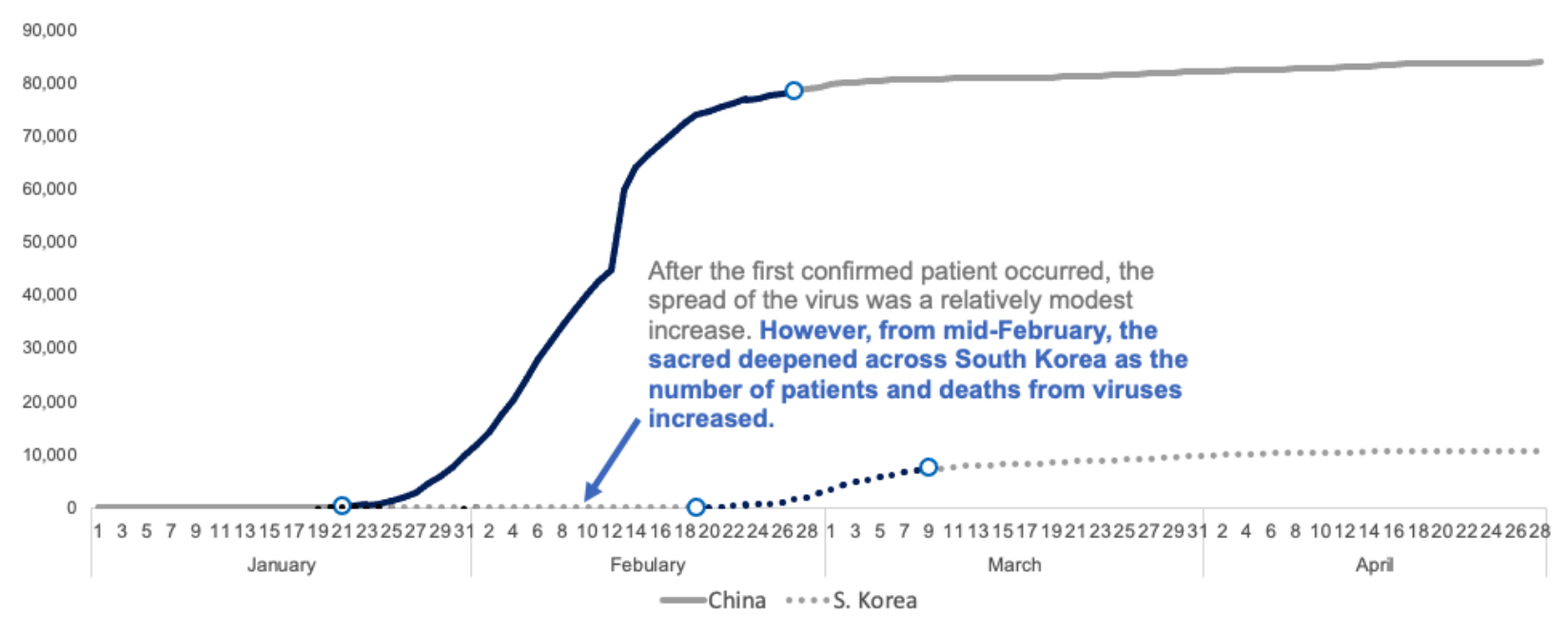

Figure 1. Statistics of confirmed COVID-19 cases in China and South Korea. In Korea, there were 29, 30, and 31 confirmed cases on 16,17, and 18 February, respectively. However, on 19 February, the number of confirmed cases increased to 46, and the number of confirmed cases increased by three digits afterwards. In the figure, confirmed cases in China are indicated by a solid line and Korea by a dotted line. 
On 23 February, the government upgraded the crisis warning to the highest level 'Red'. To maximize its effect, the government launched the Central Disaster and Safety Countermeasure Headquarters to prevent a massive spread of SARS-CoV-2 [36]. The Central Disease Control Headquarters serves as the command centre of the prevention and control efforts (head: Director of KCDC, Korea Centers for Disease Control \& Prevention). The Central Disaster Management Headquarters is responsible for disaster restoration plans, prevention countermeasures, and disaster emergency countermeasures.

\subsection{Confusing Guidelines for Mask Use}

The Korean Government provided information on the proper purchase and use of health masks for yellow and fine dust [29]. However, in the course of responding to COVID-19, government guidelines have changed several times. On 29 January, the MFDS stated that 'it is desirable to use a KF94 - KF99 grade mask' to prevent infection [37]. The reuse of a mask for an extended period was not recommended because the filter becomes contaminated, and the blocking function can be significantly reduced owing to internal moisture. However, on 5 February, the CDCH (Central Disease Control Headquarters) announced that 'hospital workers are encouraged to wear KF94 and KF99 health masks'; ordinary citizens can use KF80 or cold protection masks [38]. A week later, the MFDS and Korea Medical Association recommended the use of masks for the prevention against COVID-19 [39]. The recommendation was directed to medical workers and people with respiratory symptoms. In addition, individuals in outdoor areas that were not crowded or individuals in individual spaces were not required to wear masks. On 3 March, the CDCH and issued 'Revised Recommendations for Mask Use (Temporary Guidelines in Emergencies) [40]', which revised the existing recommendations. It was deemed unnecessary for everyone to wear a mask considering that health masks could be reused. According to these guidelines, health masks could be reused only by the same person, provided they were used temporarily and were clean.

In Korea, the first Middle East Respiratory Syndrome (MERS) case occurred on 29 May 2015; 186 patients were declared until the end of the epidemic on 23 December. The epidemic caused 38 deaths and 16,693 were contained [41]. Based on this experience, authorities and groups of experts have made recommendations to help health authorities make the best choice in times of crisis [42]. The Public Health Crisis Response Communication Guide [42] lists five reasons for the failure in crisis communication: (1) inconsistent messaging, (2) delayed release of information to the public, (3) a patriarchal attitude, (4) procrastination in addressing rumours and oboes, (5) and publicizing internal conflicts [43]. The report emphasized that the health authorities and related ministries, local governments, and cooperative organizations should maintain the cooperative system and that consistent messages should be communicated at a public location. However, the government's recommendations on the use of masks were inconsistent, which promoted anxiety among citizens. The government was accused of trying to reduce the demand for masks by changing the guidelines without scientific experiments or verification procedures. During this period, concerns about the mask shortage spread rapidly among citizens.

\subsection{Imbalance between Supply and Demand}

The several reasons that affected the mask shortage were investigated: first, the balance in the market collapsed owing to the 'cornering' of the market and hoarding of masks [44]. Since mid-February, when the number of confirmed cases rapidly increased, the price of masks has increased steeply, and the available supply has decreased sharply because distributors secured masks and sold them at high prices. However, this reason is not necessarily the only cause of the mask shortage. The government launched extensive restrictions on cornering the market for face masks and other hygiene products; nevertheless, the demand for masks increased unceasingly. Second, the raw materials required for the manufacture of masks were not imported timeously. These materials include non-woven fabrics and melt-blown filters. The manufacture of low-cost masks requires the import 
of raw materials from China; however, the COVID-19 spread in China made it difficult to import the filters and finished products, thereby preventing the national production of masks. Finally, the implementation of the government's restrictions on mask exports was delayed. As shown in Figure 2, exports of other textile products, including health masks, increased to $\$ 153.80$ million in February, which was double the amount of the previous month (\$71.38 million). Exports in February were 2159 tons, thus, 1.3 times that of the previous month and 6.3 times that of the same period last year. The higher increase in monetary value as opposed to the weight means that the export price of a mask was extremely high (Figure 3). In particular, public exports, which account for $86 \%$ of total exports, soared more than 200 times. The total export value of this item was $\$ 8.91$ million last year, which represents an average of $\$ 6.7$ million per month. Contrarily, mass imports of the same item fell by $-44.0 \%$ in February, with a greater decline percentage.

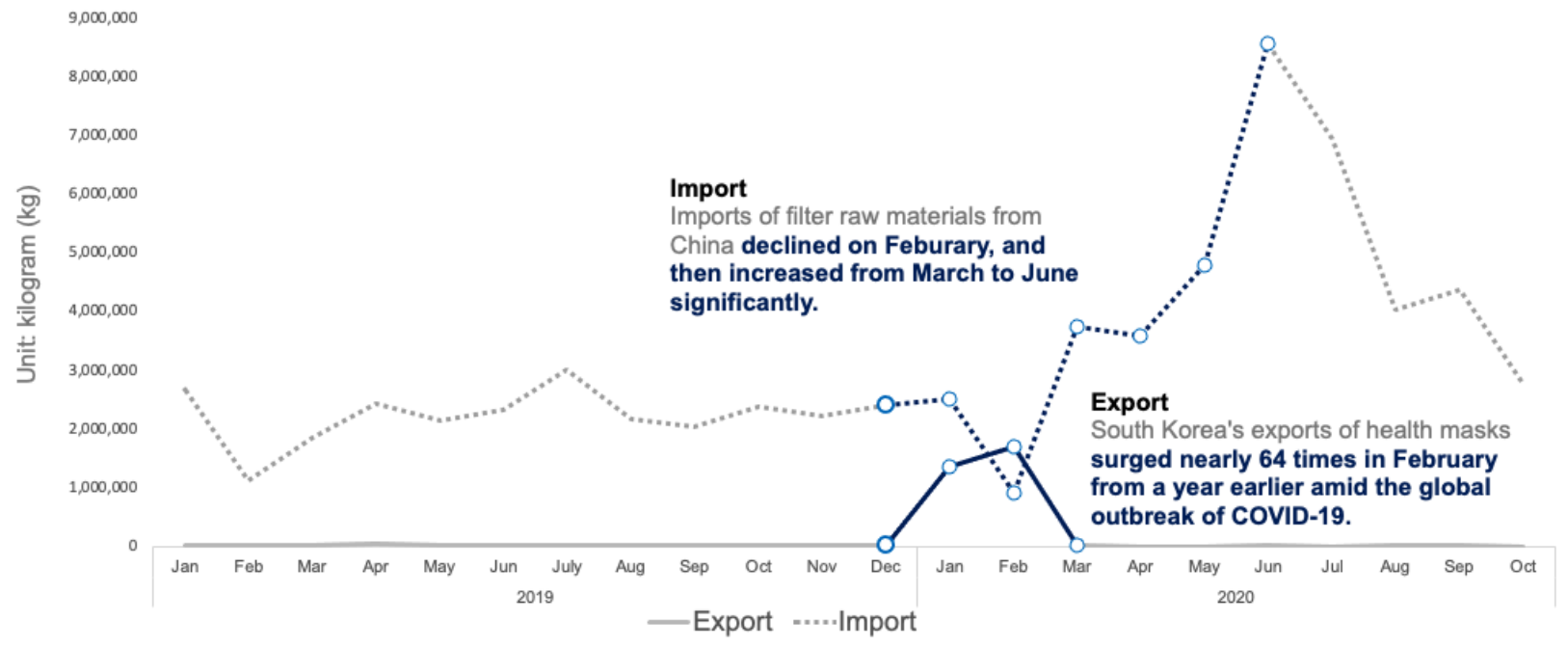

Figure 2. Exported and imported weights of face masks between 2019 and 2020 (Korea Customs Service, 2020). In the figure, exports are indicated by solid lines and imports by dotted lines.

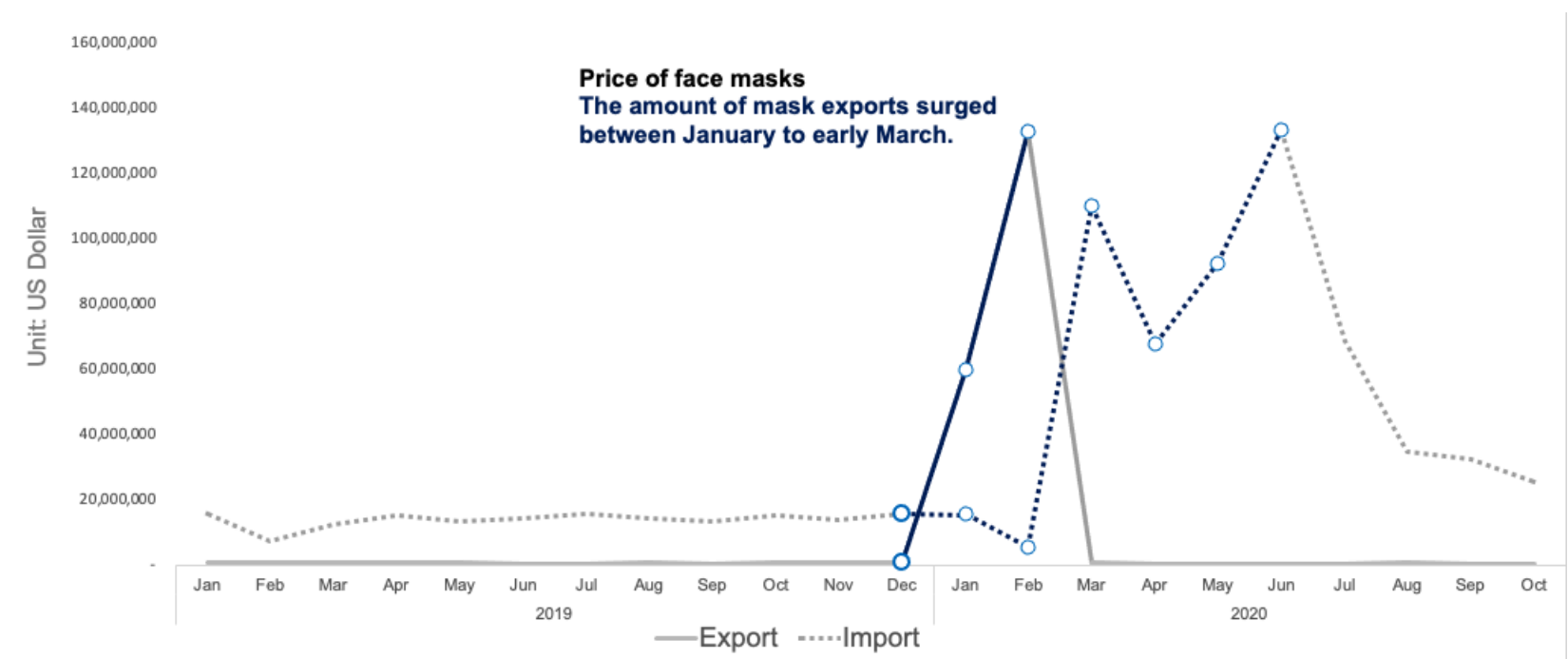

Figure 3. Export and import of face masks and its materials in amount between 2019 and 2020 (Korea Customs Service, 2020). In the figure, exports are indicated by solid lines and imports by dotted lines. 


\subsection{Face Mask Distribution System in Public}

The government announced a Five-Day Rotation Face Mask Distribution with three purchase principles for the fair distribution of masks [16]: (1) only two masks per person: each person can purchase only two masks per week from pharmacies, post offices, and Nonghyup from Monday to Sunday. If someone has bought only one mask, an additional purchase cannot be made during that week. Therefore, purchasing two masks at once is recommended. In addition, someone cannot buy more than two masks per week even if he or she was unable to purchase them during the previous week. If someone was unable to buy a mask during the week, he or she can buy them from a pharmacy on Saturdays and Sundays. However, if someone did not purchase masks in the week, he or she cannot purchase more than two in the following week. (2) Five-day rotation: To reduce the waiting time, the designated day for purchasing masks depends on the last digit of a person's birth year (or the Alien Registration Number), as shown in Table 2. For example, if someone was born in 1960, the last digit is ' 0 '; this person can purchase a mask from a pharmacy on Friday. (3) Multiple purchase monitoring: an official identification card with the Resident Registration Number (or the Alien Registration Number) is required when purchasing masks. Repurchases are impossible because ID cards are used for purchases in pharmacies in Korea, and the purchase records are shared across the nation's pharmacy network. The post offices and Nonghyup Hanaro Mart stores have also established a duplicate purchase confirmation system similar to that of the pharmacies.

Table 2. Available mask purchase days by birth year.

\begin{tabular}{lcccccc}
\hline & Monday & Tuesday & Wednesday & Thursday & Friday & Saturday/Sunday \\
\hline \multirow{2}{*}{ Last digit of birth year } & 1 & 2 & 3 & 4 & 5 & Those unable to purchase during the week \\
& 6 & 7 & 8 & 9 & 0 & \\
\hline
\end{tabular}

\section{The Impact of Open Data}

\subsection{Background}

Owing to the rapid SARS-CoV-2 spread, citizens have made various proposals for preventing infectious diseases and reducing the spread of infections during a gathering on Gwanghwamoon 1st Street (https:/ / www.gwanghwamoon1st.go.kr/front/main/ index.do. This communication platform for citizens allows the integration of ideas from ordinary people into national agendas, which are established by the Ministry of the Interior and Safety (MOIS). The Innovation Proposal Talk on Gwanghwamoon 1st Street is a forum that communicates the opinions and policies proposed by citizens to the government. Proposals with more than 30 approvals (including comments) within 30 days will receive government responses and are executed by an administrative body. The establishment of a COVID-19 Public Data Co-Response team with the title "We provide suggestions for COVID-19 and public data related to infectious diseases" was proposed (https: / / www.gwanghwamoon1st.go.kr/front/propseTalk/propseTalkViewPage. do?propse_id=7a6f646cb53c4ac39ff694522ee0c04e) during the Innovation Proposal Talk on the 4th of March. Moreover, for an effective response to infectious diseases, the team requested the disclosure of reliable government open data. In response to this, the government decided to disclose information to the private sector and released comprehensive statistics on infectious diseases, a list of screening clinics and national security hospitals, and the supply and demand status of public masks on the public data portal (http:/ / data.go.kr). In addition, the government formed a task force in partnership with the private sector to solve mask shortage problems. Several government bodies participated in the task force, such as the MOIS (Ministry of the Interior and Safety), Ministry of Science and ICT (MSIT), Ministry of Health and Welfare (MOHW), Ministry of SMEs (Small and Medium-sized Enterprises) and Startups (MSS), National Information Society Agency (NIA), and Health Insurance Review and Assessment Service (HIRA). The team discussed a collaborative approach to develop a mask inventory service that provides purchase information of masks 
on mobile and web platforms. They stated that the mask inventory service would provide comprehensive information on public masks and purchases and should, therefore, be operated at a commercial service level [16]. Various problems in the development and operation of the service include the overall policies, a scope of releasing datasets, details about each dataset, application programming interface (API) specification, and service infrastructure. The mask inventory service was launched on 10 March 2020.

\subsection{Public Distribution of Face Mask Information Service}

The service was developed with the civic hacking method. Civic hacking is a social movement that improves social problems by enabling citizens to collaborate quickly and creatively with new tools and approaches [45]. Conventional government-led methods are difficult to apply in emergencies owing to the complicated and time-consuming process. Therefore, the following three principles were selected and implemented for the rapid development and launch of the service in the private sector [16].

- $\quad$ Principle 1: the government and public institutions cannot solve everything.

- $\quad$ Principle 2: all issues and problems that may occur should be reviewed to provide a seamless service.

- $\quad$ Principle 3: all occurring issues or problems should be immediately shared and solved with all stakeholders.

The mask inventory service discloses data held by different management institutions to citizens and ensures close cooperation between them. As shown in Figure 4, the government agencies, Korean Pharmaceutical Association (KPA), Korea Post, Nonghyup, and cloud computing companies participated in developing the service. The role of the stakeholders at each stage is as follows: the HIRA offers a list of public retail platforms, such as government-designated pharmacies, post offices, and Nonghyup Hanaro Mart stores (approximately 24,000 pharmacies, 1406 post offices, and 1702 Hanaro Mart stores). The time of sales, inventory, location, and address information of the mask sales is updated every 5 min with HIRA's system, which prevents multiple mask purchases. The NIA converts the vendor addresses in HIRA's datasets into geographic coordinates and transforms the inventory status into four categories, as shown in Table 3 . The stock quantity is displayed in four assorted colors according to the number of masks in stock. They provide the open data in the format of an open API through cloud-based services supported by the private sector. A service infrastructure is essential for stable services. The private sector alliance (including Naver, KT, NHN, and Koscom) provides cloud services to companies, and developers use these complimentary services to create and operate web services.

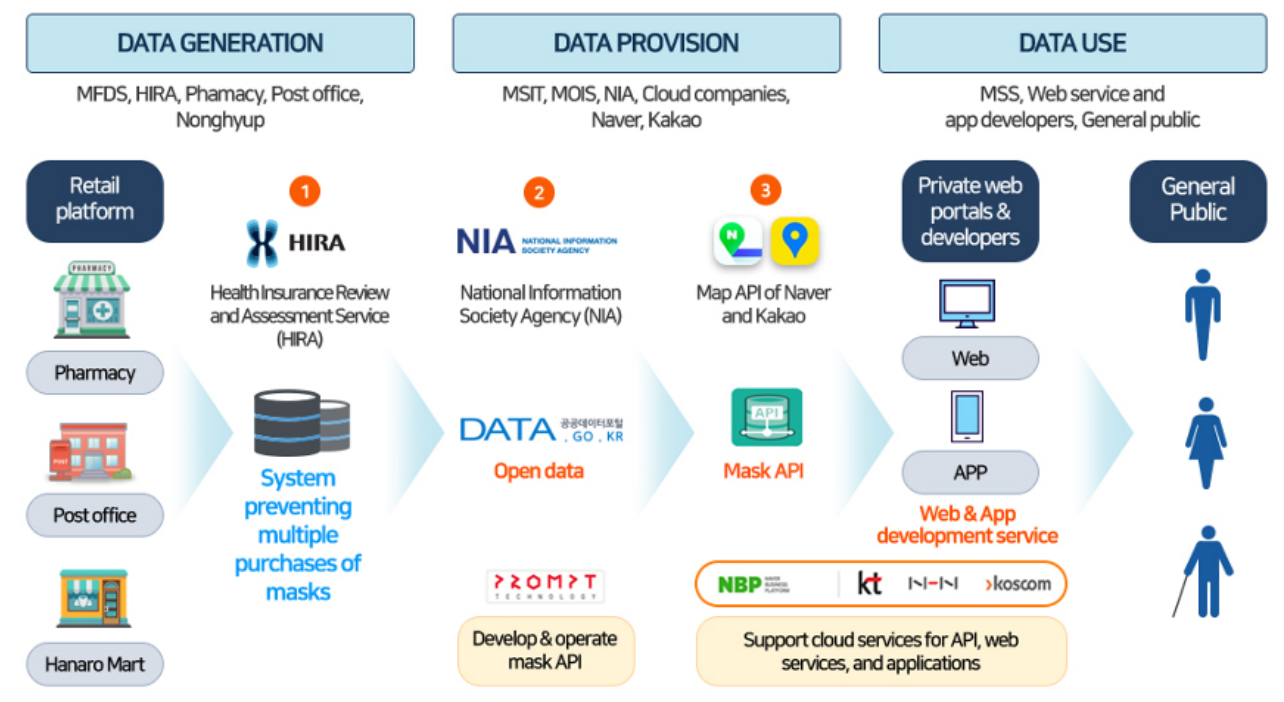

Figure 4. Public distribution of face mask information [46]. 
Table 3. Stocks separated by colors.

\begin{tabular}{ccc}
\hline Amount & Color & Description \\
\hline More than 100 & Green & Sufficient \\
Between 30 and 99 & Yellow & Moderate \\
Below 30 & Red & Insufficient \\
None available & Grey & Out of stock/Before sales \\
\hline
\end{tabular}

\subsection{Service Operations}

The release of mask sales data has instantly attracted public interest. Approximately 50 different web and mobile services were developed that use the government's open API within 10 days. As shown in Figure 5, the service has been adopted in both government bodies and private corporations in Korea. The central and local governments provided up-to-date information on their websites; in addition, KakaoMap and Naver Map (which are two of the largest IT companies in Korea) updated their maps by combining mask stocks and other COVID-19 information. Thus, citizens could visit websites created by private web portals and developers or download mobile apps to review face mask stocks of public retailers. Therefore, they could easily locate pharmacies with adequate stocks of face masks. These websites and apps required policies for stable operation because there were many technical and operational problems in the initial stages of the services.

- A method for updating sale stocks: because the new distribution system was implemented in a short time, individual pharmacies were required to understand the policies and adapt effectively on site. For example, pharmacies managed by one person or by senior employees cannot quickly update their mask stocks on the system, whereas other pharmacies distribute numeric tags and set individual start times for the mask sale. In addition, products initially packaged in units of 5 or 10 must be repackaged in sets of 2 at the pharmacy. Therefore, pharmacies require a function to allow for the update of sale times and inventory information, depending on the situation. As a result, the 'Stop Selling' button was implemented to reflect the stock of the pharmacy.

- Location information errors: the daily pharmacy information was received from HIRA in an Excel file. The NIA converted the addresses of individual pharmacies into geographical coordinates with mask stock information. However, the coordinates were not always placed according to the accurate location of a pharmacy on the map because the address was not up-to-date or in the incorrect format. Naver solved a set of coordinate errors by extracting the correct coordinate information based on the unique numbers of pharmacies (such as a nursing care symbol or business registration number). Over 2000 coordinates of more than 160 address errors were corrected, and duplicate addresses were removed.

- Agile API specification: the service operation for large-scale users presents many technical problems. For example, the provision of data can change according to subtle changes in the requirements and policies of the site. The API specification reflected changes three times, and the developer could easily investigate and apply it to the service by notifying the developer network of the disclosure and utilization of mask data.

It is worth noting that the operation problems of the service were immediately solved through the cooperation with stakeholders. As a result, the service stabilized in a short time. Once the service was launched, the number of received API calls was extremely high (between 8.3 and 9.6 million, as shown in Figure 6. The number of data calls through API cloud data reached 570 million (9.64 million per hour) between 11-31 March. The number of API calls was half that of the first service week. This indicates that citizens started to use the service efficiently by checking the real-time mask inventory at a specific location. Their satisfaction with the service was high because they could review the mask stock in real time. In addition, the mask inventory ratio differed significantly from that before 
the service launch. The sales completion rate compares the supply and sales volume of masks on a daily basis. This ratio is used to assess whether the citizen secured the allowed number of masks (i.e., sales completion rate $=$ total sales volume nationwide / total quantity of masks supplied nationwide). For example, on the 9th and 10th of March, the rates were 39.5\% and $68 \%$, respectively. In other words, the citizens were unable to purchase masks although some pharmacies had enough masks. After the service launch, the sales completion rate increased rapidly to values between $88 \%$ and $92.5 \%$. Citizens were able to review the mask stock, visit retailers nearby, and secure masks. Therefore, mask sales in pharmacies increased, and relatively unknown pharmacies increased their customer visits owing to the notification services.

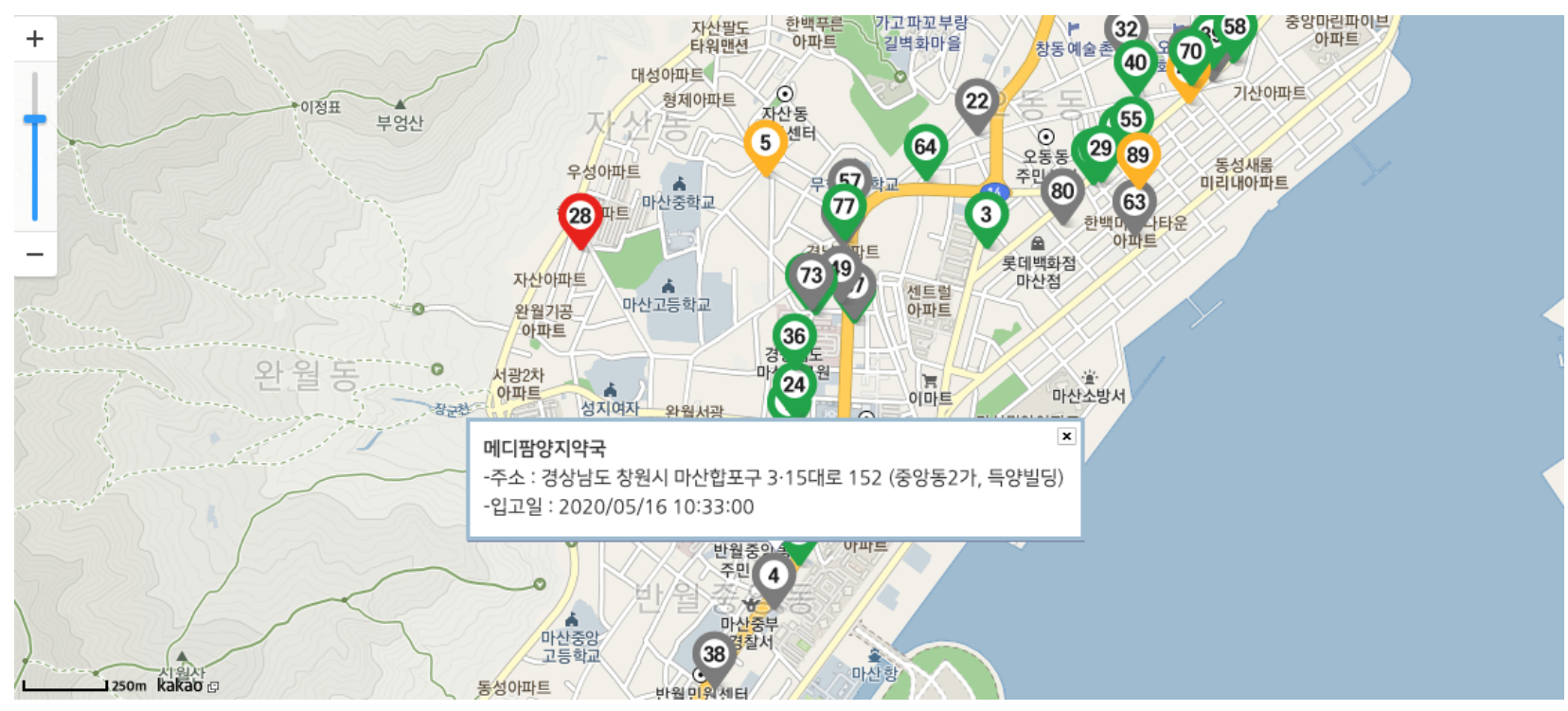

Figure 5. An example of the mask inventory service, which is provided by a local government. The numbers in the figure show the number of masks remaining. Color follows the guideline described in the Table 3 . When the user selects a circle on the map, the address of the pharmacy and the date and time the face mask was received are displayed.

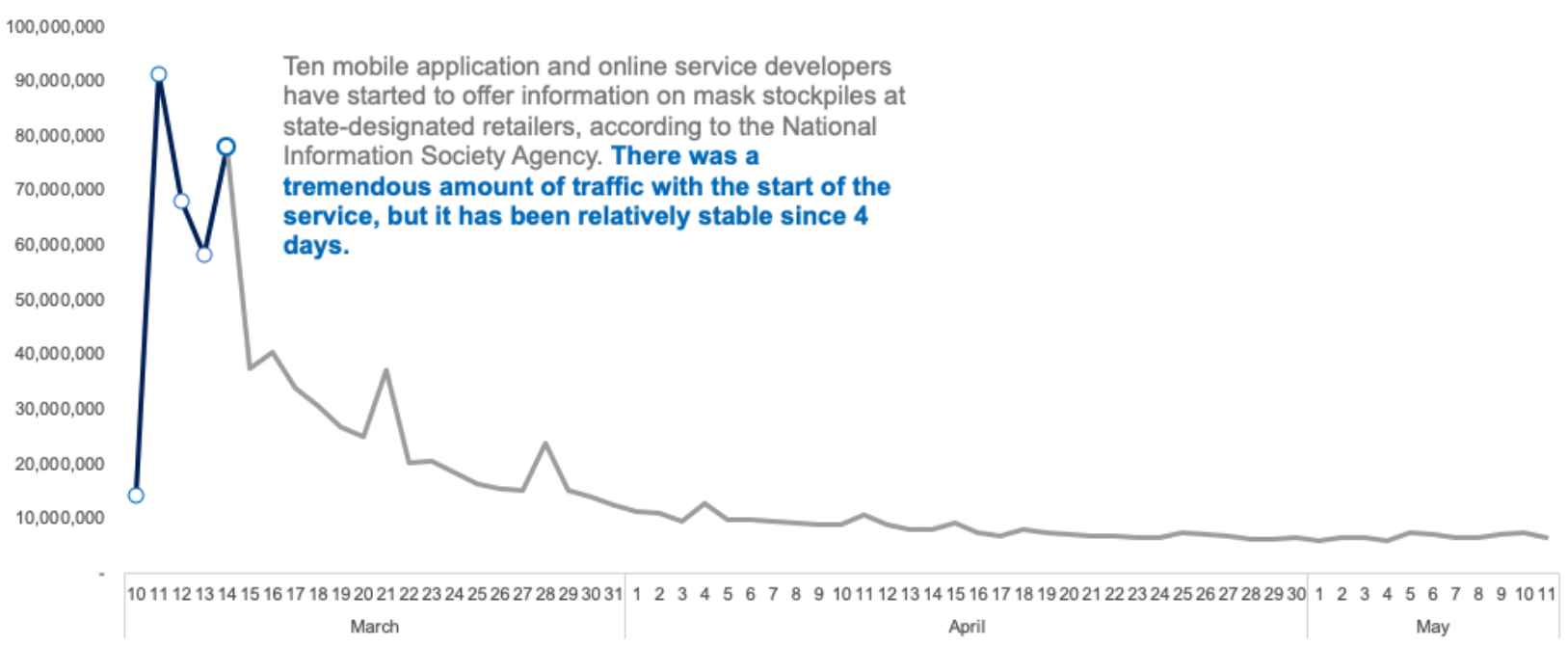

Figure 6. Application programming interface (API) calls from March to May. The number of API accesses is indicated by a solid line. 


\section{Lessons Learned}

\subsection{Results}

When the SARS-CoV-2 spread subsided and the supply of masks expanded, the controversy over masks was resolved. A brief survey on the satisfaction with the mask inventory service was conducted with 267 participants from 11-16 May. According to the results, $98.6 \%$ of the respondents were satisfied with the service. Specifically, $45 \%$ and $43 \%$ of the participants were satisfied with the government's transparency regarding the timely service and data disclosure, which reflected the needs of citizens, respectively; in addition, others were satisfied with the technical aspects, such as the convenient user interfaces. The success factors of the approach are as follows: first, all stakeholders participated from the planning stage and collaborated to find solutions. A partnership was established to connect government departments, relevant institutions, citizen developers, start-ups, and IT companies to enable effective decision-making through continuous information sharing between technology experts and the government. For example, the KPA quickly gathered the opinions of individual pharmacies and associated institutions, such as the HIRA and NIA-supported data provision, service operation (e.g., update cycles), and IT infrastructure. Second, governments and related institutions defined clear roles and responsibilities and presented the response channels. The mask inventory service is interrelated with pharmacies, developers, and citizens; thus, various inquiries and complaints could have come up. To solve effectively foreseeable problems, the roles of the related institutions were classified, and a help desk was established to respond effectively. The HIRA managed the mask purchases from pharmacies, the KPA managed inquiries about mask sales and related policies, and the NIA was responsible for notification and error reporting. In particular, related organizations shared $24 \mathrm{~h}$ response systems and manuals (also during holidays) and tried to stabilize the service. Third, the high level of cooperation from citizens for overcoming the national crisis played an important role in the success of the operation.

In the early stages of the application of the new policies, citizens had to wait for extended periods to purchase masks, while the quantity of masks as per the service was incorrect. However, the feedback and participation from citizens helped to solve the problem in a relatively short time. Complaints regarding the mask inventory service decreased rapidly from 575 on 11 March to 7 on 14 March in addition, fewer and fewer persons checked the inventory on the phone or in person at the pharmacy. Fourth, competitive IT infrastructures, such as the public data portal and cloud services, were applied in a timely manner. Korea is well equipped in terms of the public and open data environment, and a variety of open data methods are currently used across the industries, which is evidenced by the fact that Korea has retained a top position in the Organization for Economic Cooperation and Development ranking for open government data for three consecutive years [47]. The mask inventory service was developed by combining data held by various institutions with data generated in real time; good customer experience in disclosing public data is an important success factor for providing timely services.

\subsection{Discussion}

Although the disclosure of data and services developed to solve the mask shortage in a timely manner were received positively, there are a number of limitations regarding the data that must be addressed. Although the quantity and sales of masks were released every day, the disclosed data were insufficient. First, the data on the quantity of supplied masks were classified into three areas in the country, and the quantity supplied by traders in the specific area was provided. However, information that is categorized into three areas is difficult to use in the analysis of a specific area. Second, the consistency of the provided items was insufficient. Data on the quantity of supplied masks were provided by the initial three zones; however, the provisions changed after a certain time and were therefore inconsistent. Thus, the provided information can already have changed when an urgent situation is being addressed; however, data items were arbitrarily reduced. For example, after 17 April, supply data were classified into 'emergency/general' items, and 
the information of the previous three areas (regions) was lost. Third, the data values were refined. Mask supply data are now presented in tens of thousands of values. Owing to the 'two per week' criterion, the data are overly abstract (separation of items and values), which can affect the reliability of the provided data. Fourth, the format of the provided data is limited. The sales status data are provided in the Hangul (Hancom) Word Processor (HWP)/Portable Document Format (PDF) format (from HIRA) and Joint Photographic Experts Group (JPEG) format (from MOHW). Owing to the basic principles of open data, the Comma-Separated Values (CSV) format is suitable for data processing and reuse. Finally, an in-depth discussion of personal information is needed. Mask sales data is deleted after a certain period of time in accordance with the law. Since there are many concerns about the leakage or abuse of personal information in a crisis situation of the spread of COVID-19, it is necessary to discuss ways to manage personal information safely and systematically use it. In particular, the management of personal information linked to geographic information should be approached strictly.

\section{Conclusions}

This paper presents a solution for mask shortages caused by the COVID-19 outbreak; the approach is based on the disclosure of government data and timely online services. The government provides up-to-date mask inventory data, which developers of a number of applications use to help people locate pharmacies with sufficient mask stocks. Since the launch of the mask inventory service, citizens can easily locate pharmacies with adequate face mask stocks and plan their mask purchases.

The disclosure of datasets regarding the supply and demand of masks and real-time services proved to be the best practice for solving social problems based on government transparency. The government and private sector cooperated and provided tailored services for citizens, thereby contributing to solving the mask shortage in a short period of time. Thus, government policies promote fair purchase conditions because of the published mask stocks and unified mask prices. This is evaluated as a best practice for the government to implement sustainable policies in cooperation with private experts. From a social point of view, limited distribution of masks was realized through comprehensive consensus and participation of members of society.

The Korean Government announced that it would abolish the Five-Day Rotation Face Mask Distribution System in June 2020. Citizens will be able to purchase masks on any day of the week from 1 June 2020. The new weekly purchase limit is three masks per person. However, because the regions continuously report new confirmed COVID-19 cases, voluntary prevention measures for citizens are still necessary. In addition, the government and private sector must cooperate to resolve the crisis effectively. In the future, the policies for the disclosure and utilization of data at the level of cross-government bodies and the required technical standards regarding the data life cycle will be reviewed.

Funding: This research received no external funding.

Institutional Review Board Statement: Not applicable.

Informed Consent Statement: Not applicable.

Data Availability Statement: All data are publicly available on https://github.com/haklaekim/ public-mask-supply-in-korea.

Conflicts of Interest: The author declares no conflict of interest.

\section{References}

1. Mckibbin, W.; Fernando, R. The global macroeconomic impacts of COVID-19: Seven scenarios. CAMA Work. Pap. 2020, 10, 116-156. [CrossRef]

2. WHO. WHO Announces COVID-19 Outbreak a Pandemic; World Health Organization: Geneva, Switzerland, 2020. Available online: http://www.euro.who.int/en/health-topics/health-emergencies/coronavirus-covid-19/news/news/2020/3/whoannounces-covid-19-outbreak-a-pandemic (accessed on 24 December 2020). 
3. Sohrabi, C.; Alsafi, Z.; O’Neill, N.; Khan, M.; Kerwan, A.; Al-Jabir, A.; Iosifidis, C.; Agha, R. World Health Organization declares global emergency: A review of the 2019 novel coronavirus (COVID-19). Int. J. Surg. 2020, 76, 71-76. [CrossRef] [PubMed]

4. ECDC. COVID-19 Situation Update Worldwide, as of 29 May 2020; ECDC: Solna, Sweden, 2020. Available online: https: / /www.ecdc.europa.eu/en/geographical-distribution-2019-ncov-cases (accessed on 24 December 2020).

5. Fernandes, N. Economic effects of coronavirus outbreak (COVID-19) on the world economy. SSRN Electron. J. 2020, 1-33. [CrossRef]

6. Nicola, M.; Alsafi, Z.; Sohrabi, C.; Kerwan, A.; Al-Jabir, A.; Iosifidis, C.; Agha, M.; Agha, R. The socio-economic implications of the coronavirus pandemic (COVID-19): A review. Int. J. Surg. 2020, 78, 185-193. [CrossRef] [PubMed]

7. Le, T.; Andreadakis, Z.; Kumar, A.; Román, R.; Tollefsen, S.; Saville, M.; Mayhew, S. The COVID-19 vaccine development landscape. Nat. Rev. Drug Discov. 2020, 19, 305-306. [CrossRef] [PubMed]

8. Guadagno, L. Migrants and the COVID-19 Pandemic: An Initial Analysis; International Organization for Migration: Grand Saconai, Switzerland, 2020.

9. Council, E. COVID-19 Coronavirus Outbreak and the EU's Response. 2020. Available online: https:/ / www.consilium.europa $\mathrm{eu} / \mathrm{en} /$ policies/covid-19-coronavirus-outbreak-and-the-eu-s-response/ (accessed on 24 December 2020).

10. Hale, T.; Angrist, N.; Kira, B.; Petherick, A.; Phillips, T.; Webster, S. Variation in Government Response to COVID-19; Technical Report 6; Blavatnik School of Government: Oxford, UK, 2020.

11. Feng, S.; Shen, C.; Xia, N.; Song, W.; Fan, M.; Cowling, B. Rational use of face masks in the COVID-19 pandemic. Lancet Respir. Med. 2020, 8, 434-436. [CrossRef]

12. MOHW. Public Advice E Notice; Ministry of Health and Welfare: Sejong, Korea, 2020. Available online: http://ncov.mohw.go.kr/ en /infoBoardList.do?brdId=14\&brdGubun=141\&dataGubun=\&ncvContSeq=\&contSeq=\&board_id=\&gubun= (accessed on 24 December 2020).

13. Long, Y.; Hu, T.; Liu, L.; Chen, R.; Guo, Q.; Yang, L.; Cheng, Y.; Huang, J.; Du, L. Effectiveness of N95 respirators versus surgical masks against influenza: A systematic review and meta-analysis. J. Evid. Based Med. 2020, 13, 93-101. [CrossRef] [PubMed]

14. Yonhap. Supply Shortage of Face Masks in S. Korea due to Chinese Buying Binge; Yonhap: Seoul, Korea, 2020. Available online: http:/ / www.koreaherald.com/view.php?ud=20200203000556 (accessed on 24 December 2020).

15. Lee, H.S. Face Mask Shortage Spreads to Korea, Too. 2020. Available online: http://www.koreabiomed.com/news/articleView. html?idxno=7331 (accessed on 24 December 2020).

16. The Government of the Republic of Korea. How Korea Responded to a Pandemic Using ICT: Flattening the Curve on COVID-19; Technical Report; The Government of the Republic of Korea: Seoul, Korea, 2020.

17. WHO. Novel Coronavirus (2019- $n$ CoV) Situation Report-11; Technical Report; World Health Organization: Geneva, Switzerland, 2020. Available online: https://www.who.int/docs/default-source/coronaviruse/situation-reports/20200131-sitrep-11-ncov. pdf?sfvrsn=de7c0f7_4 (accessed on 24 December 2020).

18. WHO. Water, Sanitation, Hygiene, and Waste Management for the COVID-19 Virus: Interim Guidance; Technical Report; World Health Organization: Geneva, Switzerland, 2020. Available online: https://apps.who.int/iris/rest/bitstreams/1275547/retrieve (accessed on 24 December 2020).

19. Cook, T. Personal protective equipment during the COVID-19 pandemic-A narrative review. Anaesthesia 2020, 75, 1121-1121. [CrossRef] [PubMed]

20. Society, R. Face Masks for the General Public; Technical Report; Royal Society DELVE Initiative: London, UK, 2020. Available online: https:/ / rs-delve.github.io/reports/2020/05/04/face-masks-for-the-general-public.html (accessed on 24 December 2020).

21. WHO. Advice on the Use of Masks in the Context of COVID-19; World Health Organization: Geneva, Switzerland, 2020. Available online: https:/ / www.who.int/publications/i/item/advice-on-the-use-of-masks-in-the-community-during-home-care-andin-healthcare-settings-in-the-context-of-the-novel-coronavirus-(2019-ncov)-outbreak (accessed on 24 December 2020).

22. Howard, J.; Huang, A.; Li, Z.; Tufekci, Z.; Ždímal, V.; Westhuizen, H.M.; Delft, A.; Price, A.; Fridman, L.; Tang, L.H.; et al. Face masks against COVID-19: An evidence review. Preprints 2020, 2020040203. [CrossRef]

23. Eikenberry, S.E.; Mancuso, M.; Iboi, E.; Phan, T.; Eikenberry, K.; Kuang, Y.; Kostelich, E.; Gumel, A.B. To mask or not to mask: Modeling the potential for face mask use by the general public to curtail the COVID-19 pandemic. Infect. Dis. Model. 2020, 5, 293-308. [PubMed]

24. Chan, T. Universal masking for COVID-19: Evidence, ethics and recommendations. BMJ Glob. Health 2020, 5, e002819. [CrossRef] [PubMed]

25. Cheng, V.; Wong, S.C.; Chuang, V.; So, S.; Chen, J.; Sridhar, S.; To, K.; Chan, J.; Hung, I.; Ho, P.L.; et al. The role of community-wide wearing of face mask for control of coronavirus disease 2019 (COVID-19) epidemic due to SARS-CoV-2. J. Infect. 2020, 81, 107-114. [CrossRef] [PubMed]

26. Stutt, R.; Retkute, R.; Bradley, M.; Gilligan, C.; Colvin, J. A modelling framework to assess the likely effectiveness of facemasks in combination with 'lock-down' in managing the COVID-19 pandemic. Proc. R. Soc. A Math. Phys. Eng. Sci. 2020, 476, 20200376. [CrossRef] [PubMed]

27. Mi-Na, K. What type of face mask is appropriate for everyone-mask-wearing policy amidst COVID-19 pandemic? J. Korean Med. Sci. 2020, 35, e186. [CrossRef]

28. Lee, E.; Chen, Y.Y.; McDonald, M.; O'Neill, E. Dynamic response systems of healthcare mask production to COVID-19: A case study of Korea. Systems 2020, 8, 18. [CrossRef] 
29. NIFDSE. Guidelines for Standards of Health Masks (In Korean); Technical Report; National Institute of Food and Drug Safety Evaluation: Cheongju, Korea, 2019. Available online: https:/ /www.nifds.go.kr/brd/m_15/down.do?brd_id=167\&seq=12791\& data_tp $=$ A\&file_seq $=1$ (accessed on 24 December 2020).

30. Ham, S.H.; Won-Jun, C.; Wan-Hyung, L.; Seong-Kyu, K. Characteristics of health masks certified by the Ministry of Food and Drug Safety. Korean Soc. Environ. Health 2019, 45, 134-141.

31. Ahn, S.H. Mask Sales Surged due to Concerns About Pneumonia in Wuhan. Out of Stock (in Korean). 2020. Available online: https://biz.chosun.com/site/data/html_dir/2020/01/28/2020012802731.html (accessed on 24 December 2020).

32. MOHW. IMS Meeting for Novel Coronavirus Presided Over by the Prime Minister; Technical Report; Ministry of Health and Welfare: Sejong, Korea, 2020. Available online: http:/ / www.mohw.go.kr/eng/nw/nw0101vw.jsp?PAR_MENU_ID=1007\&MENU_ID=10 0701\&page $=3 \& C O N T \_S E Q=352865$ (accessed on 24 December 2020).

33. Korea, H. Korean Government Announced that No Need to Postpone or Cancel the Mass Event Such as KPOP Concert. 2020. Available online: https: / / www.habkorea.net/korean-government-announced-that-no-need-to-postpone-or-cancel-the-massevent-such-as-kpop-concert/ (accessed on 24 December 2020).

34. Choe, S. South Korean Leader Said Coronavirus Would 'Disappear.' It Was a Costly Error. 2020. Available online: https: / /www.nytimes.com/2020/02/27/world/asia/coronavirus-south-korea.html (accessed on 24 December 2020).

35. KMA. Medical Consultation Conducts Survey on Corona 19 (In Korean); KMA: Seoul, Korea, 2020. Available online: http: / / www.mdon.co.kr/news/article.html?no=26450 (accessed on 24 December 2020).

36. MOPSS. Enforcement Decree of the Framework Act on the Management of Disasters and Safety. 2018. Available online: http:/ / elaw.klri.re.kr/eng_service/lawView.do?hseq=46616\&lang=ENG (accessed on 24 December 2020).

37. MFDS. Announcement: Eui-Kyung Lee, Minister of Food and Drug Safety, Urgent Inspection of Mask Production Site (In Korean). 2020. Available online: https:/ / tinyurl.com/ya938s5y (accessed on 24 December 2020).

38. CDCH. Announcement: Domestic Occurrence of New Coronavirus Infections (in Korean); CDCH: Hongkong, China, 2020. Available online: http:/ / www.mohw.go.kr/react/al/sal0301vw.jsp?PAR_MENU_ID=04\&MENU_ID=0403\&page=1\&CONT_SEQ=352708 (accessed on 24 December 2020).

39. MFDS; KMA. Announcement: Recommendations for the Use of Masks to Prevent COVID-19. 2020. Available online: http: / / ncov.mohw.go.kr/shBoardView.do?brdId=2\&brdGubun=21\&ncvContSeq=239 (accessed on 24 December 2020).

40. CDCH. Announcement: Revised Recommendations for Mask Use (Temporary Guidelines in Emergencies); CDCH: Hongkong, China, 2020. Available online: https:/ / www.mfds.go.kr/brd/m_99/view.do?seq=43991\&srchFr=\&srchTo=\&srchWord=\&srchTp=\&itm_ seq_1=0\&itm_seq_2=0\&multi_itm_seq=0\&company_cd=\&company_nm=\&page=1 (accessed on 24 December 2020).

41. MOHW. THE 2015 MERS Outbreak in the Republic of Korea: Learning from MERS; Technical Report; Ministry of Health and Welfare: Sejong, Korea, 2016. Available online: http:/ / nih.go.kr/board/board.es?mid=a20504000000\&bid=0014\&tag=\&act=view\&list_ no $=128379$ (accessed on 24 December 2020).

42. KCDC. Crisis, Emergency, Risk Communication; Technical Report; Ministry of Health and Welfare: Sejong, Korea, 2017. Available online: http: / / www.cdc.go.kr/board.es?mid=a20507020000\&bid=0019\&act=view\&list_no=138067\&tag=\&nPage=16 (accessed on 24 December 2020).

43. Lee, H.Y.; Oh, M.N.; Park, Y.S.; Chu, C.; Son, T.J. Public health crisis preparedness and response in Korea. Osong Public Health Res. Perspect. 2013, 4, 278-284. [CrossRef] [PubMed]

44. MFDS. List of COVID-19 In-Vitro Diagnostic Devices Approved by MFDS; Technical Report; Ministry of Food and Drug Safety: Sejong, Korea, 2020. Available online: https:/ / www.mfds.go.kr/eng/brd/m_65/down.do?brd_id=engcovid1902\&seq=1\&data_ tp=A\&file_seq=1 (accessed on 24 December 2020).

45. Hou, Y.; Lampe, C. Sustainable hacking: Characteristics of the design and adoption of civic hacking projects. In Proceedings of the 8th International Conference on Communities and Technologies, New York, NY, USA, 26-30 June 2017; Association for Computing Machinery: New York, NY, USA, 2017; pp. 125-134.

46. NIA. Korean ICT Services Against COVID-19 Pandemic; Technical Report; National Information Society Agency: Daegu/Seoul, Korea, 2020. Available online: https: / www.nia.or.kr/common/board /Download.do?bcIdx=22151\&cbIdx=39485\&fileNo=9 (accessed on 24 December 2020).

47. OECD. Government at a Glance 2019; OECD Publishing: Paris, France, 2019. 